\title{
Erratum to: Electromagnetic interference shielding effects of polyaniline-coated multi-wall carbon nanotubes/maghemite nanocomposites
}

\author{
Jumi Yun • Hyung-Il Kim
}

Published online: 19 May 2012

(C) Springer-Verlag 2012

Erratum to: Polym. Bull. (2012) 68:561-573

DOI 10.1007/s00289-011-0651-4

Due to an oversight the following reference was missing from the reference list. "Polyaniline MWCNT composites for microwave absorption Material Chemistry Physics 113, 2009, 919-926."

The full citation is as follows:

Parveen Saini, Veena Choudhary, B.P. Singh, R.B. Mathur, S.K. Dhawan, Polyaniline-MWCNT nanocomposites for microwave absorption and EMI shielding, Materials Chemistry and Physics, Volume 113, Issues 2-3, 15 February 2009, Pages 919-926, ISSN 0254-0584, doi:10.1016/j.matchemphys.2008.08.065.

The online version of the original article can be found under doi:10.1007/s00289-011-0651-4.

J. Yun · H.-I. Kim ( $\)$

Department of Fine Chemical Engineering and Applied Chemistry, BK21-E2M,

Chungnam National University, Daejeon 305-764, Republic of Korea

e-mail: hikim@cnu.ac.kr 